\title{
COMPLETION OF THE LONG DURATION WEAR TEST OF THE NASA HERMES HALL THRUSTER
}

2019 AIAA Propulsion \& Energy Forum August 19, 2019

Jason D. Frieman, Hani Kamhawi, Jon Mackey, Thomas Haag, Peter Y. Peterson, and Daniel

A. Herman

NASA Glenn Research Center

James Gilland

Ohio Aerospace Institute

and

Richard R. Hofer

Jet Propulsion Laboratory 


\section{Introduction: HERMeS Development}

- High-power (40-kW) SEP capability has been identified as enabling for near term and future NASA exploration architectures

- Example: Power and Propulsion Element of NASA's Gateway

- $\quad$ Since 2012, NASA has been developing the Hall Effect Rocket with Magnetic Shielding (HERMeS) to serve as a SEP capability building block

- Technology development transitioned to Aerojet Rocketdyne via Advanced Electric Propulsion System (AEPS) contract

- NASA continues to support AEPS development via mission risk reduction activities including wear testing of technology demonstration unit (TDU) thrusters

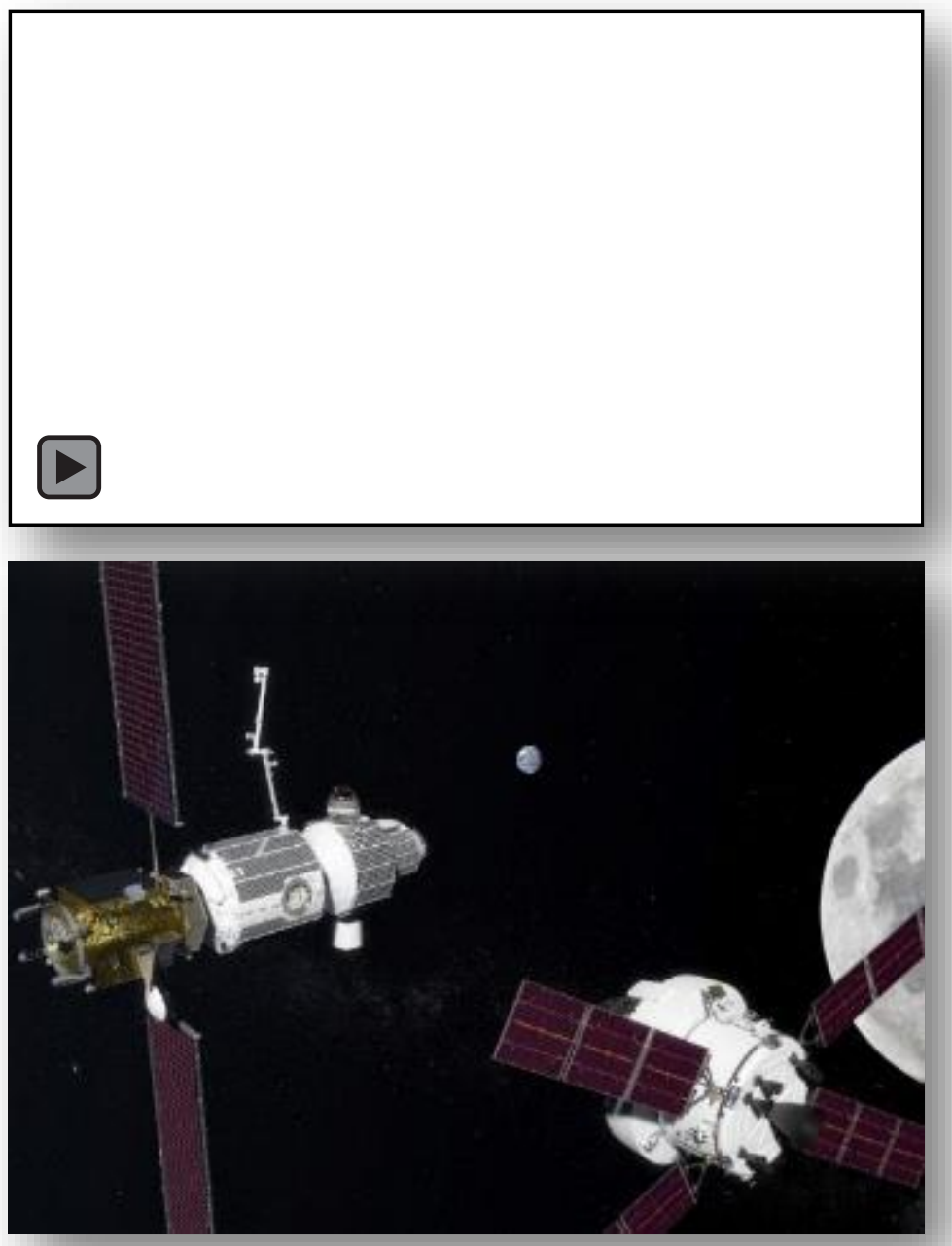




\section{Introduction: HERMeS Wear Tests}

- 2016 TDU-1 Wear Test: AIAA Paper 2016-5025

- Goal: provide first quantitative insight into wear and performance trends over an extended period of thruster operation

- $1700 \mathrm{~h}$ of operation at $600 \mathrm{~V} / 12.5 \mathrm{~kW}$

- 2017 TDU-3 Short Duration Wear Test (SDWT): IEPC Paper 2017-207

- Goal: quantify the impact of operating condition on thruster life

- $200 \mathrm{~h}$ segments (7x) each performed at a different operating condition

> 2017-2018 TDU-3 Long-Duration Wear Test (LDWT)

- Pathfinder test for the planned 23 kh AEPS life and qualification campaign intended to:

1. Quantify the performance, stability, plume, and wear trends of TDU-3 over at least 3,000 hours of operation using methods planned for AEPS testing.

2. Quantify the effect of back-sputtered facility material on TDU-3 over at least 3,000 hours of operation.

3. Develop institutional guidelines and procedures for operation of long-duration tests in Vacuum Facility 5 (VF-5) at NASA GRC. 


\section{Test Summary}

- The TDU-3 LDWT was conducted between 10/23/2017 and 10/4/2018 and accumulated approximately $3,570 \mathrm{~h}$ of total operating time in six segments:

- I: Repeat of the TDU-1 wear test

- II-IV: Assess impact of discharge voltage and magnetic field strength on component wear

- V: Assess performance and wear using an alternate pole cover material (carboncarbon composite) with increased strength and crack resistance

- VI: Assess the impact of facility pressure on performance and wear

*All segments completed at a discharge current of approximately $20.8 \mathrm{~A}$

\begin{tabular}{|c|c|c|c|c|c|c|}
\hline Segment & I & II & III & IV & V & VI \\
\hline Operating Condition & $\begin{array}{c}600 \mathrm{~V} / \\
1 \mathrm{~B}\end{array}$ & $\begin{array}{c}300 \mathrm{~V} / \\
1 \mathrm{~B}\end{array}$ & $\begin{array}{l}300 \mathrm{~V} / \\
0.75 \mathrm{~B}\end{array}$ & $\begin{array}{l}300 \mathrm{~V} \\
11.5 \mathrm{~B}\end{array}$ & $\begin{array}{c}600 \mathrm{~V} / \\
1 \mathrm{~B}\end{array}$ & $\begin{array}{c}600 \mathrm{~V} / \\
1 \mathrm{~B}\end{array}$ \\
\hline Facility Pressure ( $\mu$ Torr) & 5.7 & 4.2 & 4.1 & 4.2 & 4.3 & 11.7 \\
\hline Duration (h) & 1015 & 252 & 214 & 240 & 1579 & 270 \\
\hline
\end{tabular}




\section{Experimental Apparatus: Thruster and Facility}

\section{HERMeS TDU-3}

- Same thruster used for SDWT with minor modifications:

- Thickness and position of cathode keeper

- New magnet coils (field shape unaltered)

- Changes relative to TDU-1 detailed by Kamhawi et al. (IEPC Paper 2017-392)

- Resulted in minimal variation in operating characteristics

- Thruster electrically configured per recommendations from Peterson et al. (AIAA Paper 2016-5027)

- Thruster body electrically tied to cathode

- Dielectric coating on all surfaces within $1 \mathrm{~m}$ of exit plane

- Power and propellant supplied using calibrated commercial laboratory systems

- Flow rate uncertainty: $1 \%$

- Voltage uncertainty: $\pm 0.06 \mathrm{~V}$

- Current uncertainty: $\pm 0.03 \mathrm{~A}$

\section{GRC VF-5}

- Nominal pumping speed: $\sim 700 \mathrm{kl} / \mathrm{s}$ on xenon

- Nominal operating pressure: $\sim 4.5 \mu$ Torr at $12.5 \mathrm{~kW}$ throttle point

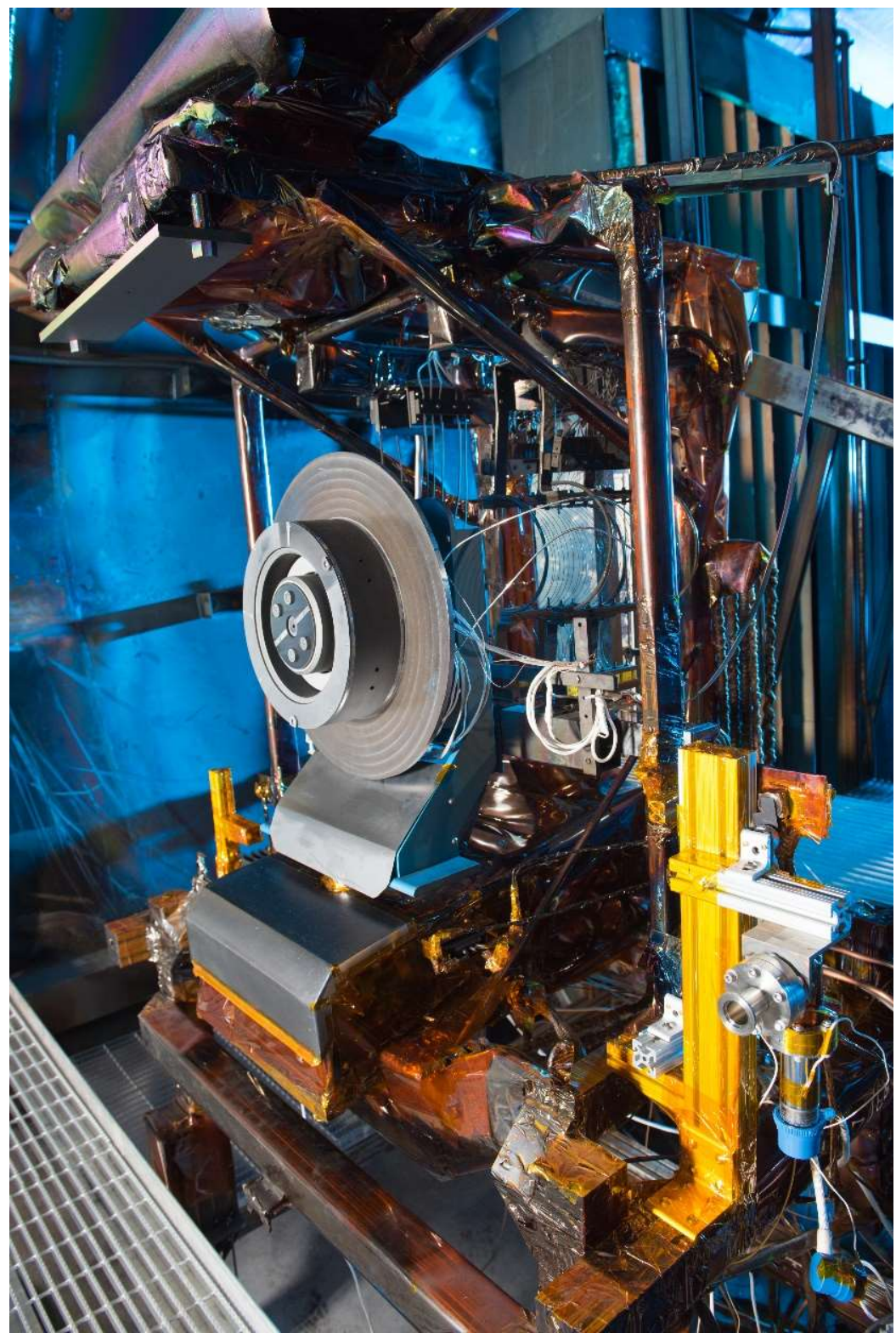




\section{Experimental Apparatus: Diagnostics}

\section{Diagnostics}

- Thrust measured with an inverted pendulum thrust stand ( \pm 0.8\% uncertainty) (AIAA Paper 2018-4516)

- $\quad$ Plasma probe package mounted to a two-axis positioning system containing (AIAA Paper 2016-4828):

- Faraday probe (FP) swept continuously over $\pm 110^{\circ}$ at five distances from exit plane

- Retarding potential analyzer (RPA) and Langmuir probe (LP) sampled at several polar angles at one distance

- ExB (Wien filter spectrometer) sampled on thruster centerline at one distance

- Quartz Crystal Microbalances (QCMs) (AIAA Paper 20164941)

- 3 mounted at a distance of $1 \mathrm{~m}$ radially outward from centerline in the thruster exit plane

- $\quad$ Pressure measured with a hot-cathode ionization gauge

- EP configured: Xe-calibrated, elbow with additional plasma screen, and housing grounded to facility

- Located $0.7 \mathrm{~m}$ radially outward, $0.08 \mathrm{~m}$ upstream, and $0.6 \mathrm{~m}$ below the thruster centerline

- Two auxiliary gauges present
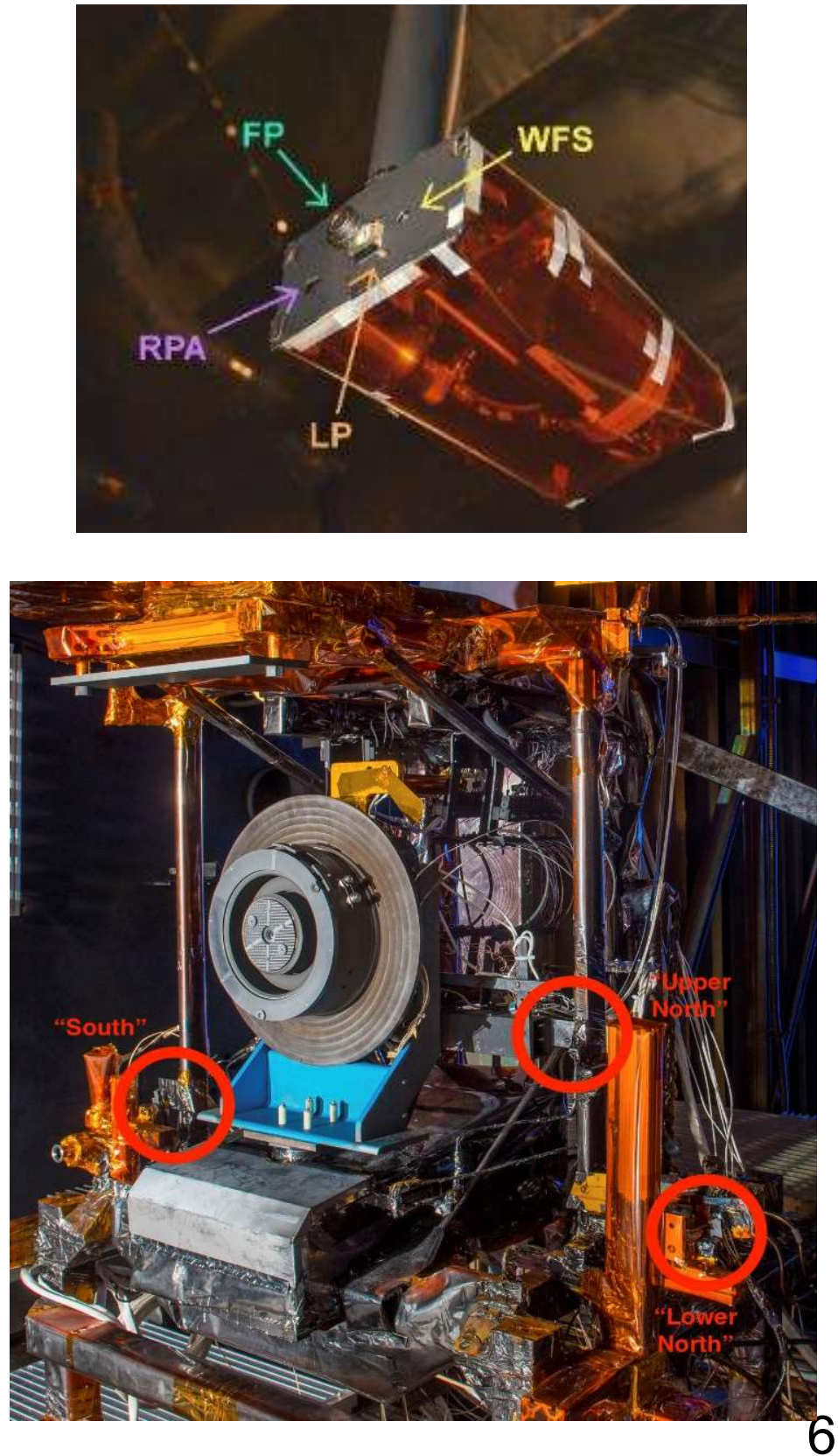


\section{Experimental Apparatus: Wear Measurements}

- Inner front pole cover (IFPC), keeper, and outer front pole cover (OFPC) modified to enable wear measurements

- Graphite components polished pre-test to maximize surface uniformity

- Composite materials were not polished

- Graphite masks installed to provide unexposed reference surfaces:

- IFPC: two graphite strips covering approximately $95 \%$ of radius

- Keeper: graphite ring with a tab protruding radially inward

- OFPC: series of graphite strips covering approximately $95 \%$ of radius

- Erosion measurements made with a chromatic, white-light, non-contact profilometer

- Data analyzed per ISO 5436-1 guidance for a type A1 step

- Typical uncertainties $\pm 2 \mu \mathrm{m}$ accounting for:

- Instrument error

- Surface roughness

- Non-flat surface geometry
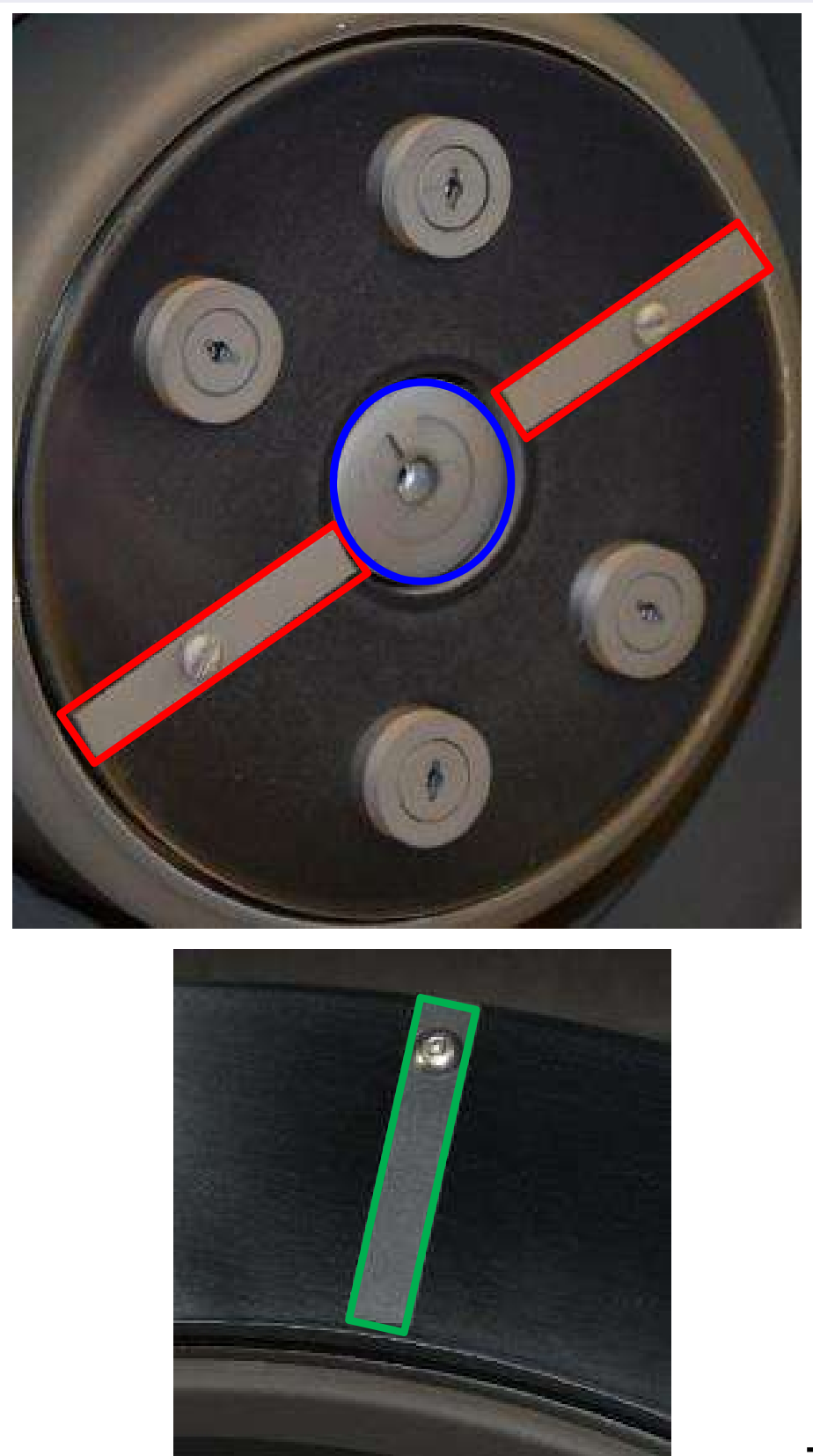


\section{Results: Performance}

\section{Performance Results}

- Thruster performance and stability characterized periodically at 6 RFCs

- Accounted for $~ 5 \%$ of total operating time

- Performance varied by less than the measurement uncertainty over the course of the LDWT

- TDU-3 performance matched results from previous wear tests to within the thrust measurement uncertainty $( \pm 5 \mathrm{mN})$

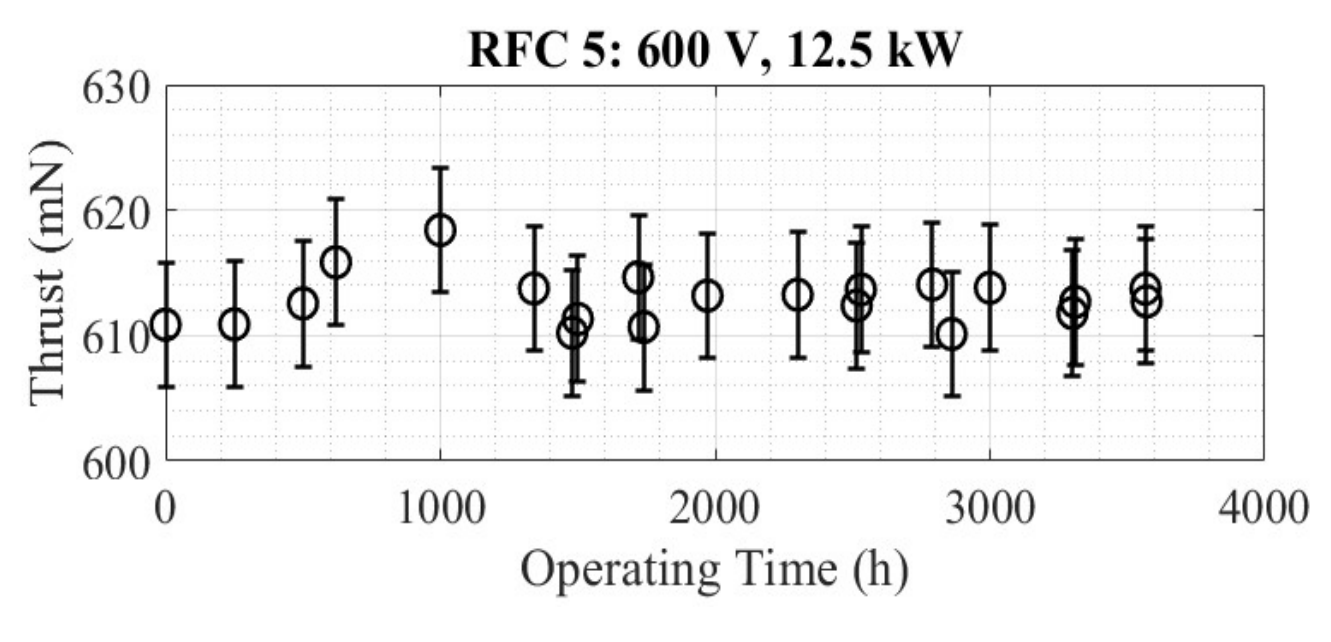

\begin{tabular}{|cc|c|c|c|c|}
\hline \multirow{2}{*}{ RFC } & \multicolumn{2}{|c|}{ TDU-1 Wear Test } & \multicolumn{2}{c|}{ TDU-3 LDWT } \\
\cline { 3 - 6 } & $\begin{array}{c}\text { Thrust } \\
(\mathbf{m N})\end{array}$ & $\begin{array}{c}\text { Standard } \\
\text { Deviation }(\mathbf{m N})\end{array}$ & $\begin{array}{c}\text { Thrust } \\
(\mathbf{m N})\end{array}$ & $\begin{array}{c}\text { Standard } \\
\text { Deviation } \mathbf{( m N})\end{array}$ \\
\hline $\mathbf{1}$ & $300 \mathrm{~V}, 2.7 \mathrm{~kW}$ & - & - & 167.5 & 2.4 \\
$\mathbf{2}$ & $300 \mathrm{~V}, 6.3 \mathrm{~kW}$ & 393.1 & 2.8 & 395.5 & 2.2 \\
$\mathbf{3}$ & $400 \mathrm{~V}, 8.3 \mathrm{~kW}$ & 477.5 & 1.9 & 479.1 & 2.1 \\
$\mathbf{4}$ & $500 \mathrm{~V}, 10.4 \mathrm{~kW}$ & 544.8 & 6.7 & 545.7 & 2.4 \\
$\mathbf{5}$ & $600 \mathrm{~V}, 12.5 \mathrm{~kW}$ & 610.1 & 2.4 & 612.9 & 2.0 \\
$\mathbf{6}$ & $630 \mathrm{~V}, 13.1 \mathrm{~kW}$ & - & - & 630.3 & 2.2 \\
\hline
\end{tabular}




\section{Results: Discharge Current Oscillations}
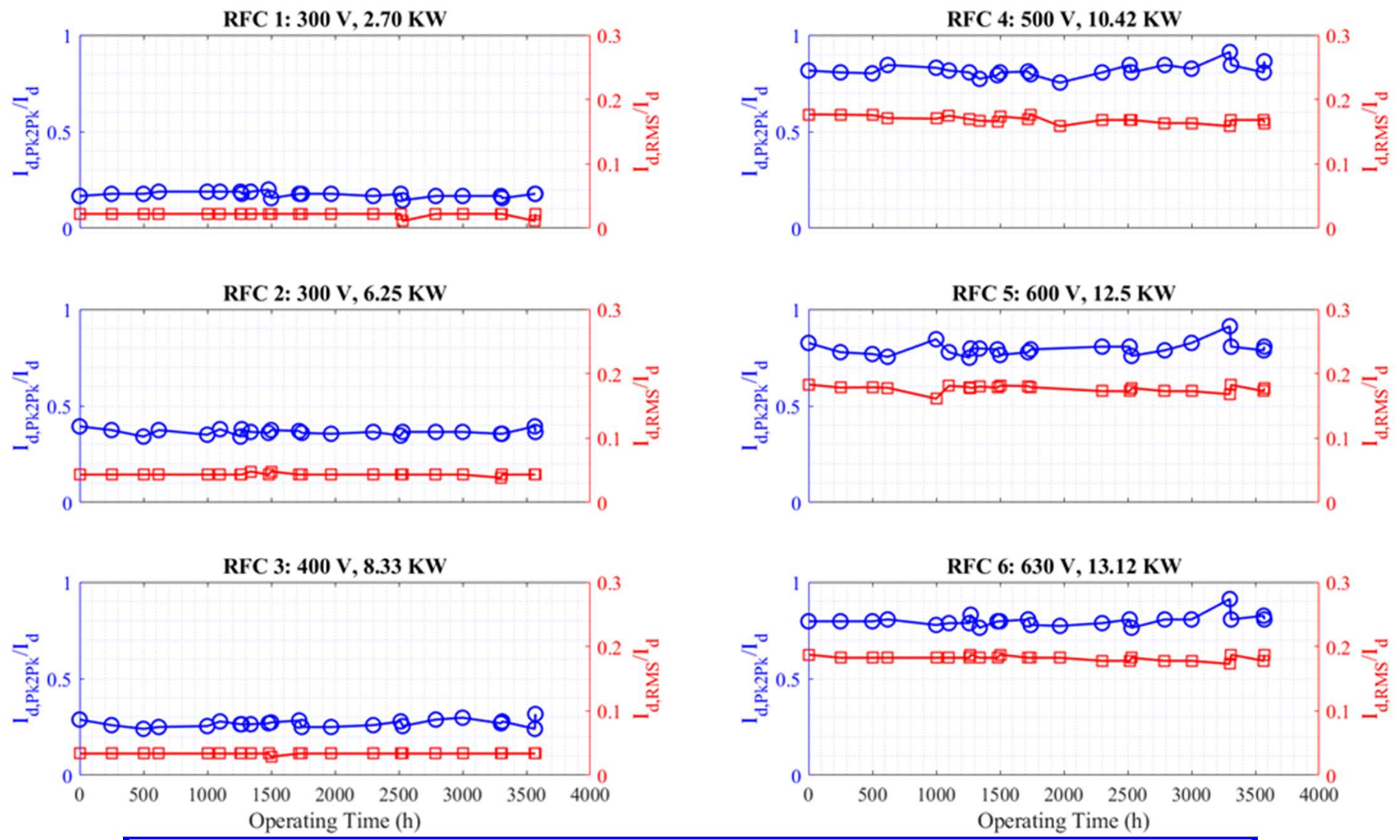

Discharge current oscillations varied by less than the uncertainty during LDWT and when compared against previous TDU wear tests 


\section{Results: Plume and Backsputter}

\section{Plume Properties}

- The standard deviation of all measured plume properties was less than $5 \%$ over the course of the LDWT:

- Charge-weighted Divergence Angle: $19.7 \pm 0.3^{\circ}$ $(1.6 \%)$

- Ion Beam Current: $18.9 \pm 0.6$ A (3.2\%)

- High-energy Polar Angle: $71.9 \pm 2.9^{\circ}(4 \%)$

- Most-probable Voltage: $578 \pm 18 \mathrm{~V}(3.2 \%)$

- All plume measurements consistent with values obtained during previous TDU tests

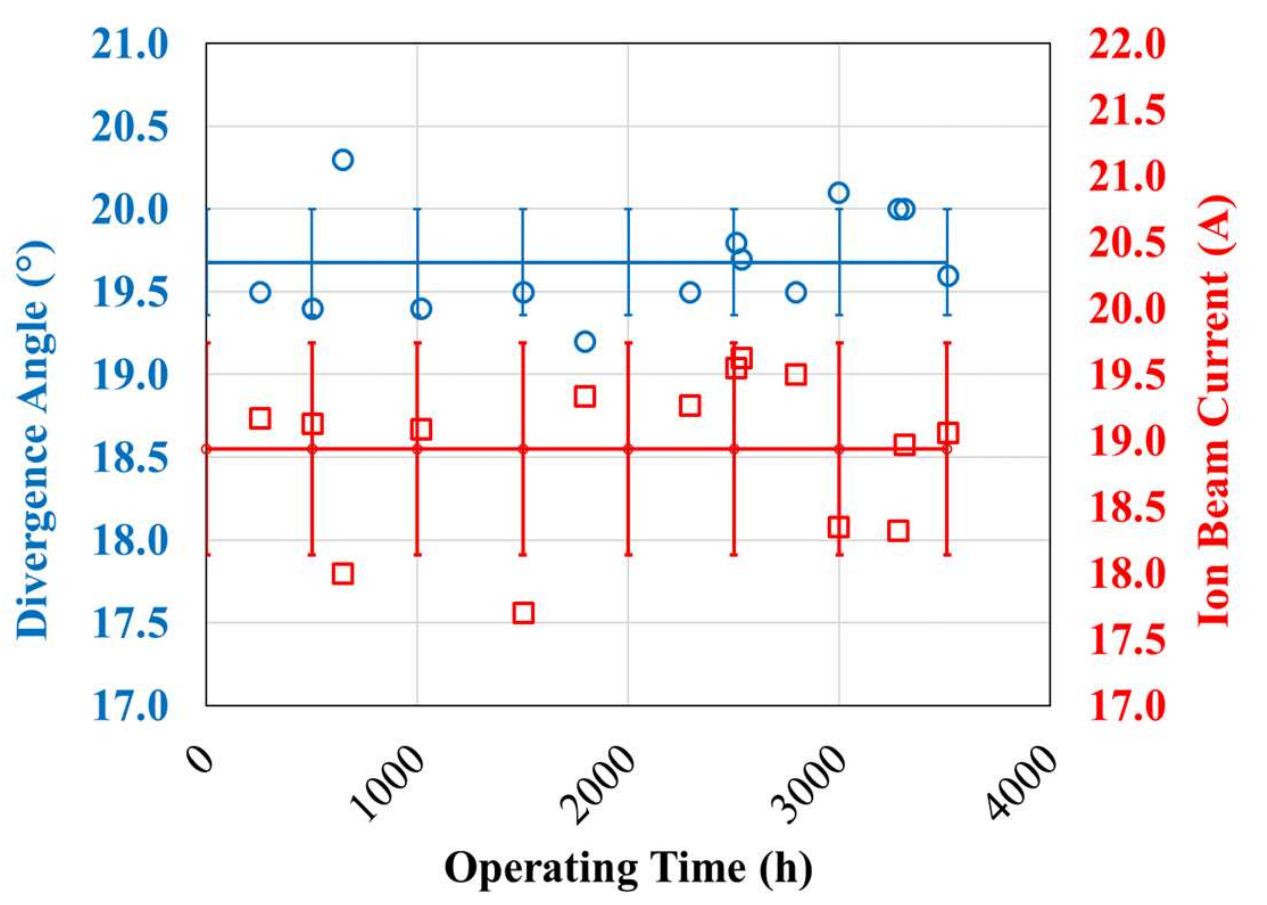




\section{Results: Plume and Backsputter}

\section{Plume Properties}

- The standard deviation of all measured plume properties was less than 5\% over the course of the LDWT:

- Charge-weighted Divergence Angle: $19.7 \pm 0.3^{\circ}$ $(1.6 \%)$

- $\quad$ Ion Beam Current: $18.9 \pm 0.6$ A (3.2\%)

- High-energy Polar Angle: $71.9 \pm 2.9^{\circ}(4 \%)$

- Most-probable Voltage: $578 \pm 18 \mathrm{~V}(3.2 \%)$

All plume measurements consistent with values obtained during previous TDU tests

\section{Facility Backsputter}

- Consistent with previous tests, facility backsputter rates were at all times less than $2 \mu \mathrm{m} / \mathrm{kh}$

- Operation at $300 \mathrm{~V}$ reduced backsputter rates by $10-15 \%$ relative to $600 \mathrm{~V}$

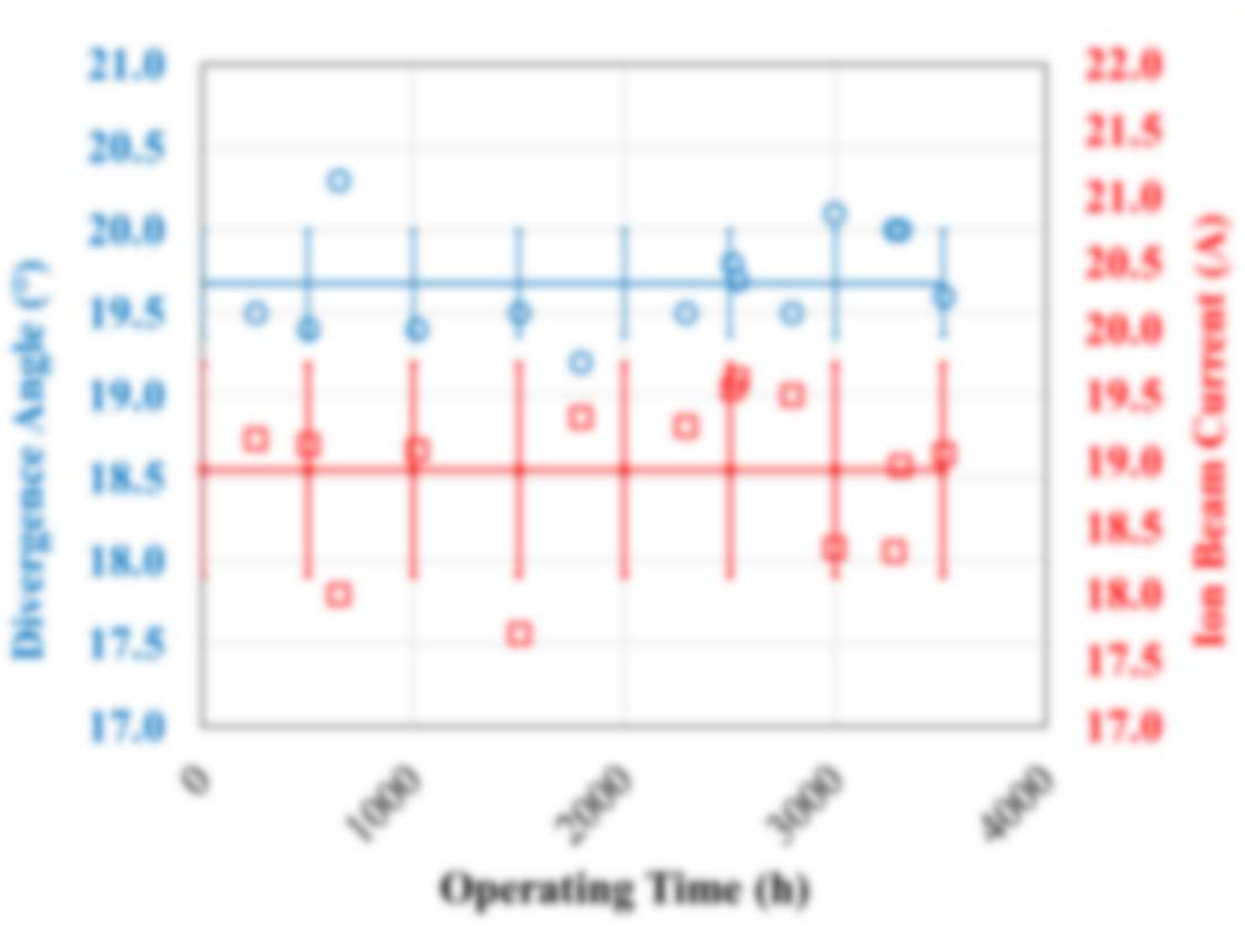

\begin{tabular}{|c|c|c|c|c|}
\hline \multirow{3}{*}{ Location } & \multicolumn{2}{|c|}{$300 \mathrm{~V} / 6.25 \mathrm{~kW}$} & \multicolumn{2}{c|}{$\mathbf{6 0 0 \mathrm { V } / 1 2 . 5 \mathrm { kW }}$} \\
\cline { 2 - 5 } & $\begin{array}{c}\text { Average } \\
(\boldsymbol{\mu \mathrm { m }} / \mathbf{k h})\end{array}$ & $\begin{array}{c}\boldsymbol{\sigma} \\
(\boldsymbol{\mu m} / \mathbf{k h})\end{array}$ & $\begin{array}{c}\text { Average } \\
(\boldsymbol{\mu m} / \mathbf{k h})\end{array}$ & $\begin{array}{c}\sigma \\
(\boldsymbol{\mu m} / \mathbf{k h})\end{array}$ \\
\hline Outer N & - & - & 1.56 & 0.22 \\
Inner N & 1.14 & 0.13 & 1.24 & 0.28 \\
$\mathbf{S}$ & 1.40 & 0.17 & 1.67 & 0.12 \\
\hline
\end{tabular}




\section{Results: Plume and Backsputter}

\section{Plume Properties}

- The standard deviation of all measured plume properties was less than 5\% over the course of the LDWT:

- Charge-weighted Divergence Angle: $19.7 \pm 0.3^{\circ}$ $(1.6 \%)$

- Ion Beam Current: $18.9 \pm 0.6$ A (3.2\%)

- High-energy Polar Angle: $71.9 \pm 2.9^{\circ}(4 \%)$

- Most-probable Voltage: $578 \pm 18$ V (3.2\%)

All plume measurements consistent with values obtained during previous TDU tests

\section{Facility Backsputter}

- Consistent with previous tests, facility backsputter rates were at all times less than $2 \mu \mathrm{m} / \mathrm{kh}$

- Operation at $300 \mathrm{~V}$ reduced backsputter rates by $10-15 \%$ relative to $600 \mathrm{~V}$

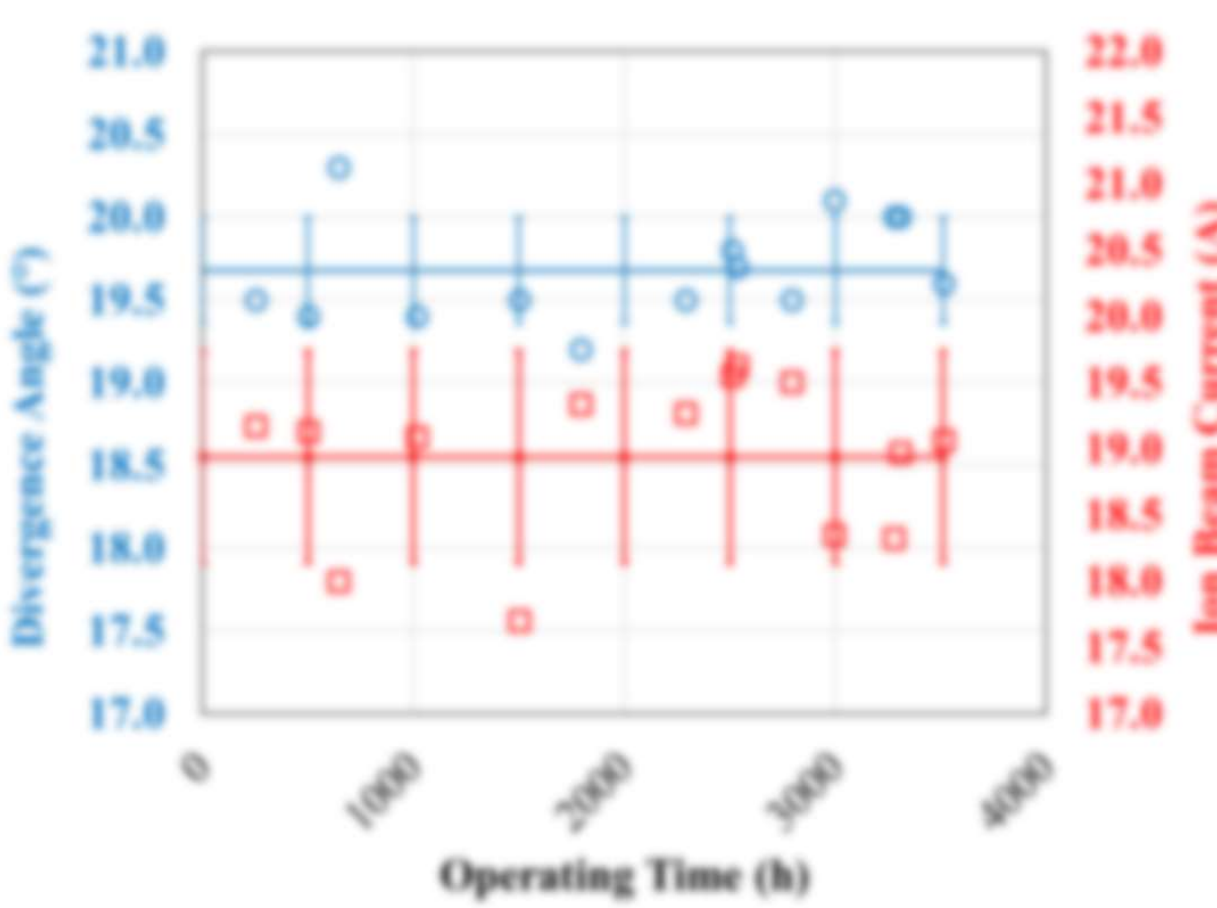

\begin{tabular}{|c|c|c|c|c|}
\hline \multirow[b]{2}{*}{ Location } & \multicolumn{2}{|c|}{$300 \mathrm{~V} / 6.25 \mathrm{~kW}$} & \multicolumn{2}{|c|}{$600 \mathrm{~V} / 12.5 \mathrm{~kW}$} \\
\hline & $\begin{array}{l}\text { Average } \\
(\mu \mathrm{m} / \mathrm{kh})\end{array}$ & $\begin{array}{c}\sigma \\
(\mu \mathrm{m} / \mathrm{kh})\end{array}$ & $\begin{array}{l}\text { Average } \\
(\mu \mathrm{m} / \mathrm{kh})\end{array}$ & $\begin{array}{c}\sigma \\
(\mu \mathrm{m} / \mathrm{kh})\end{array}$ \\
\hline Outer N & - & - & 1.56 & 0.22 \\
\hline Inner N & 1.14 & 0.13 & 1.24 & 0.28 \\
\hline $\mathbf{s}$ & 1.40 & 0.17 & 1.67 & 0.12 \\
\hline
\end{tabular}

Performance, stability, and plume properties varied by less than the uncertainty during LDWT and when compared against previous TDU wear tests 


\section{Results: Carbon Composite IFPC Wear}

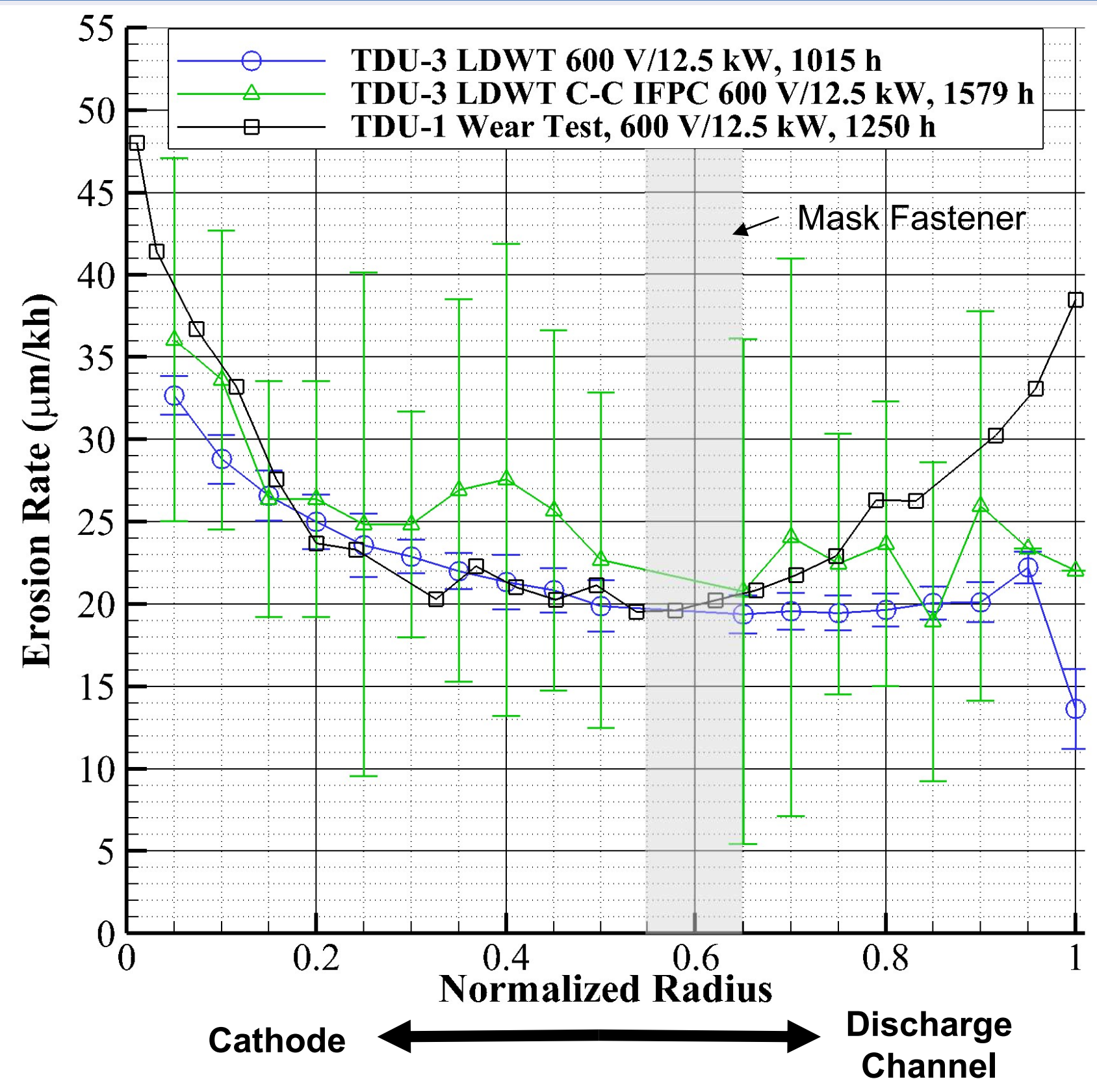

\section{Key Observations:}

1) The erosion rates of the composite IFPC matched those obtained with graphite pole covers to within the uncertainty

2) Woven structure of the composite IFPC yielded increased surface roughness and the presence of surface features equal in dimension to eroded steps $\rightarrow$ increased measurement uncertainty

3) Wear of composite IFPC maintains azimuthal symmetry 


\section{Results: Carbon Composite IFPC Wear}

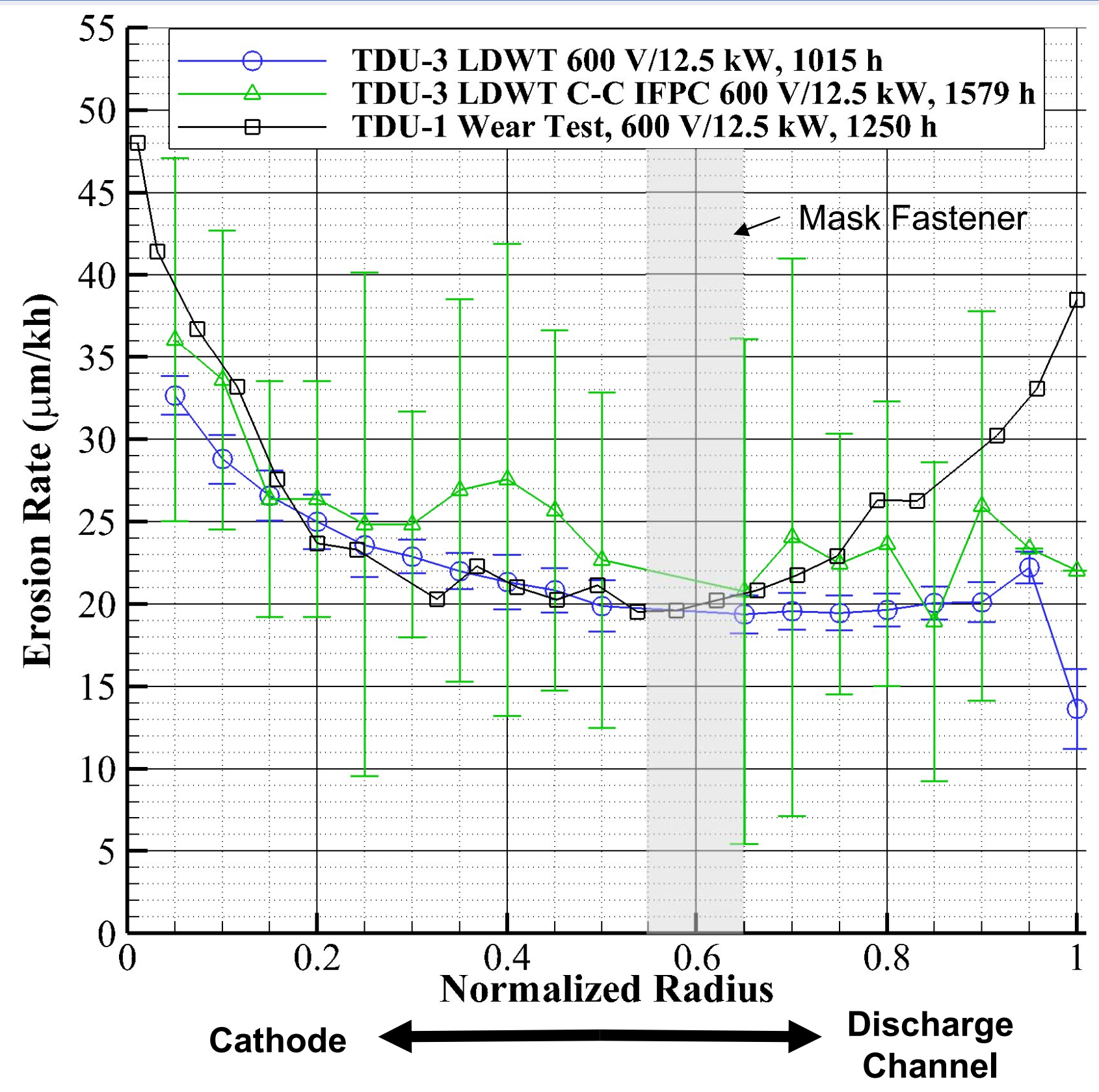

\section{Key Observations:}

1) The erosion rates of the composite IFPC matched those obtained with graphite pole covers to within the uncertainty

2) Woven structure of the composite IFPC yielded increased surface roughness and the presence of surface features equal in dimension to eroded steps $\rightarrow$ increased measurement uncertainty

\section{3) Wear of composite IFPC maintains azimuthal symmetry}




\section{Results: Carbon Composite IFPC Wear}

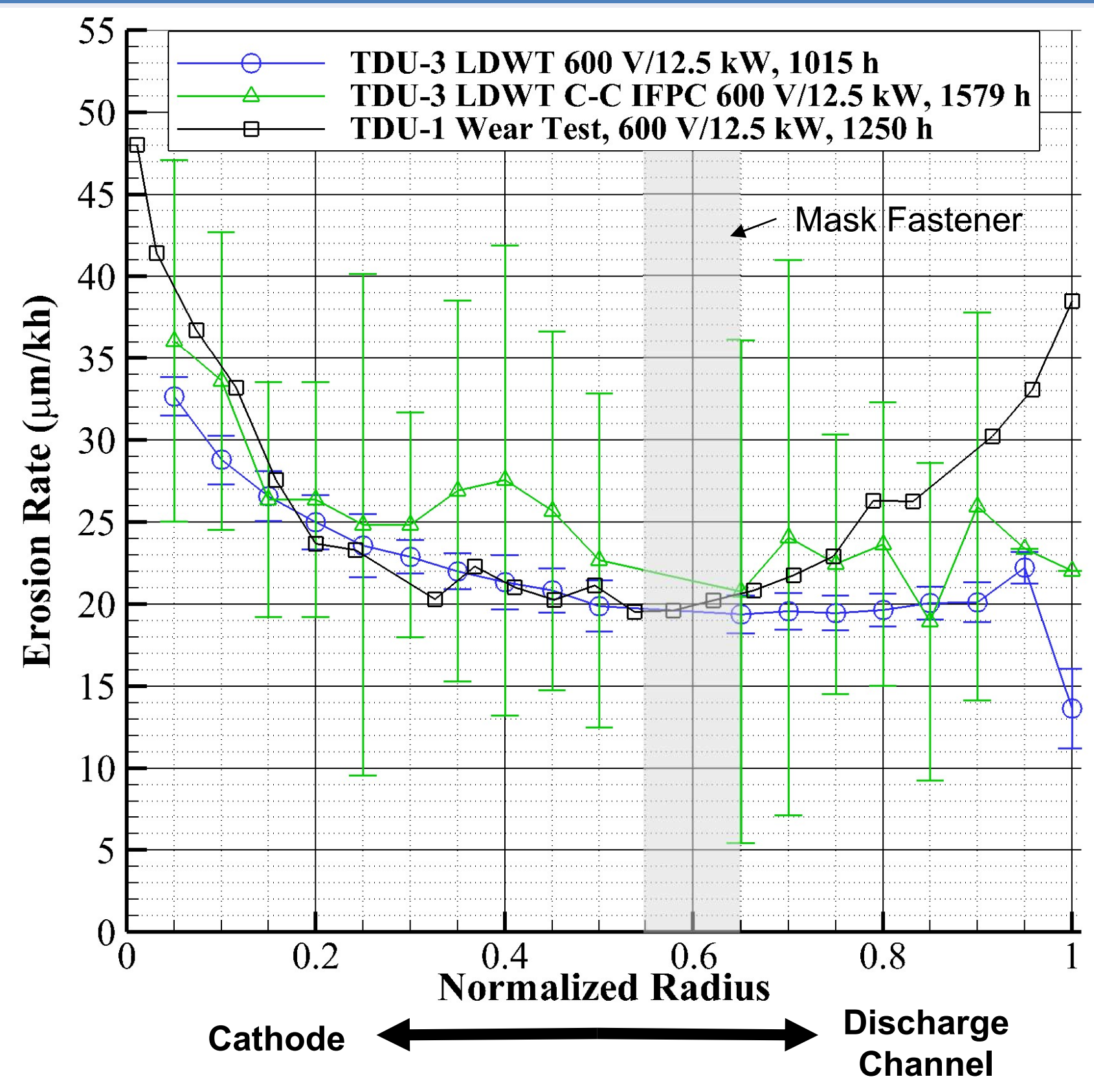

Key Observations:

1) The erosion rates of the

composite IFPC matched

those obtained with

graphite pole covers to

within the uncertainty

2) Woven structure of the composite IFPC yielded increased surface roughness and the presence of surface features equal in dimension to eroded steps $\rightarrow$ increased measurement uncertainty

3) Wear of composite IFPC maintains azimuthal symmetry 


\section{Results: OFPC Wear}

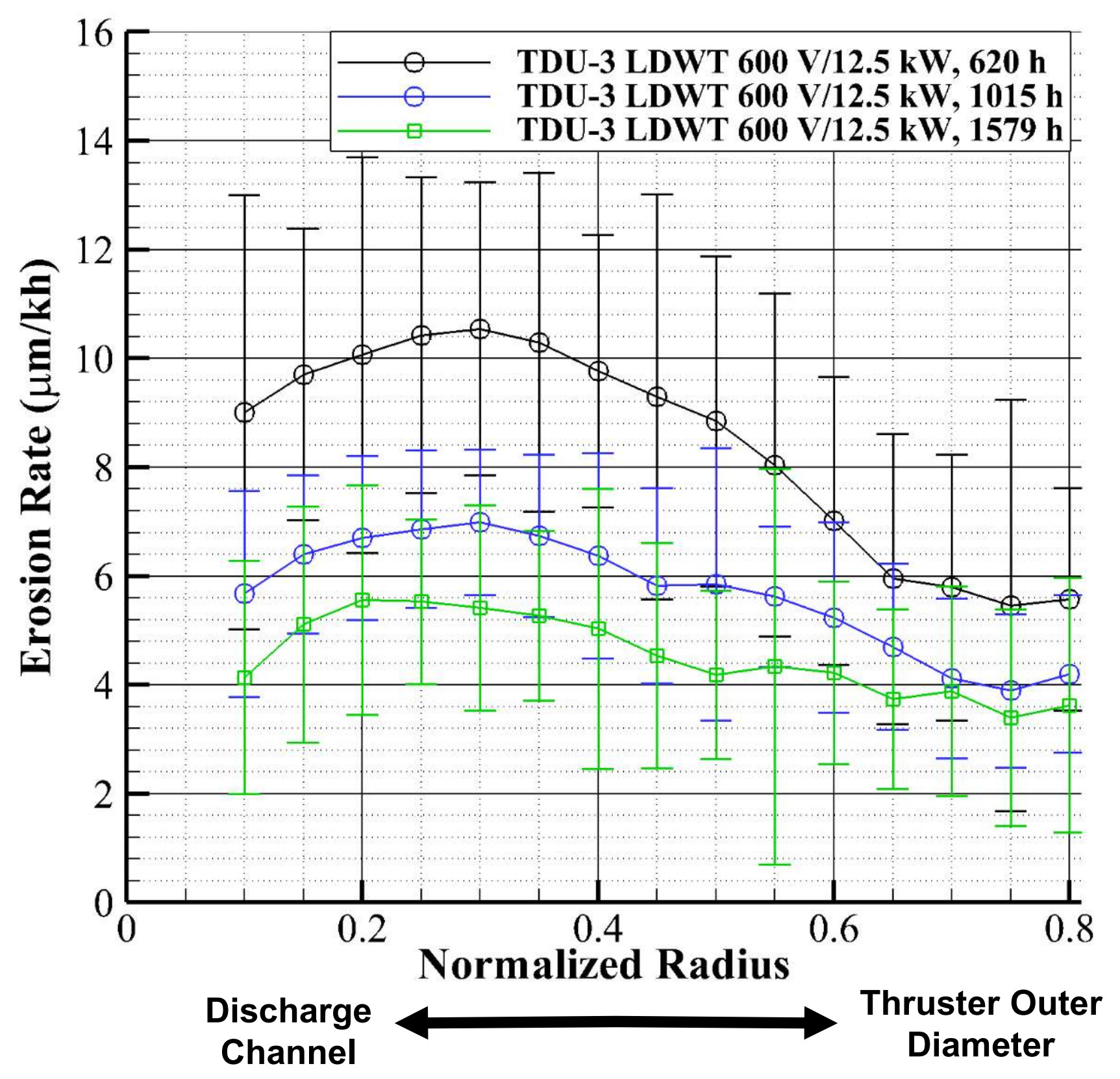

\section{Key Observations:}

1) OFPC erosion rates appear to decrease with operating time

- $46 \%$ reduction between $620 \mathrm{~h}$ and $1579 \mathrm{~h}$

- Matches trends previously observed with the IFPC

2) Wear rates impacted by pre-test surface finish

- Plotted rates are for polished regions of OFPC

- No measurable erosion detected on unpolished sections of OFPC

3) Results support hypothesis that apparent time variation in wear is driven by pole cover roughening during operation 


\section{Results: OFPC Wear}

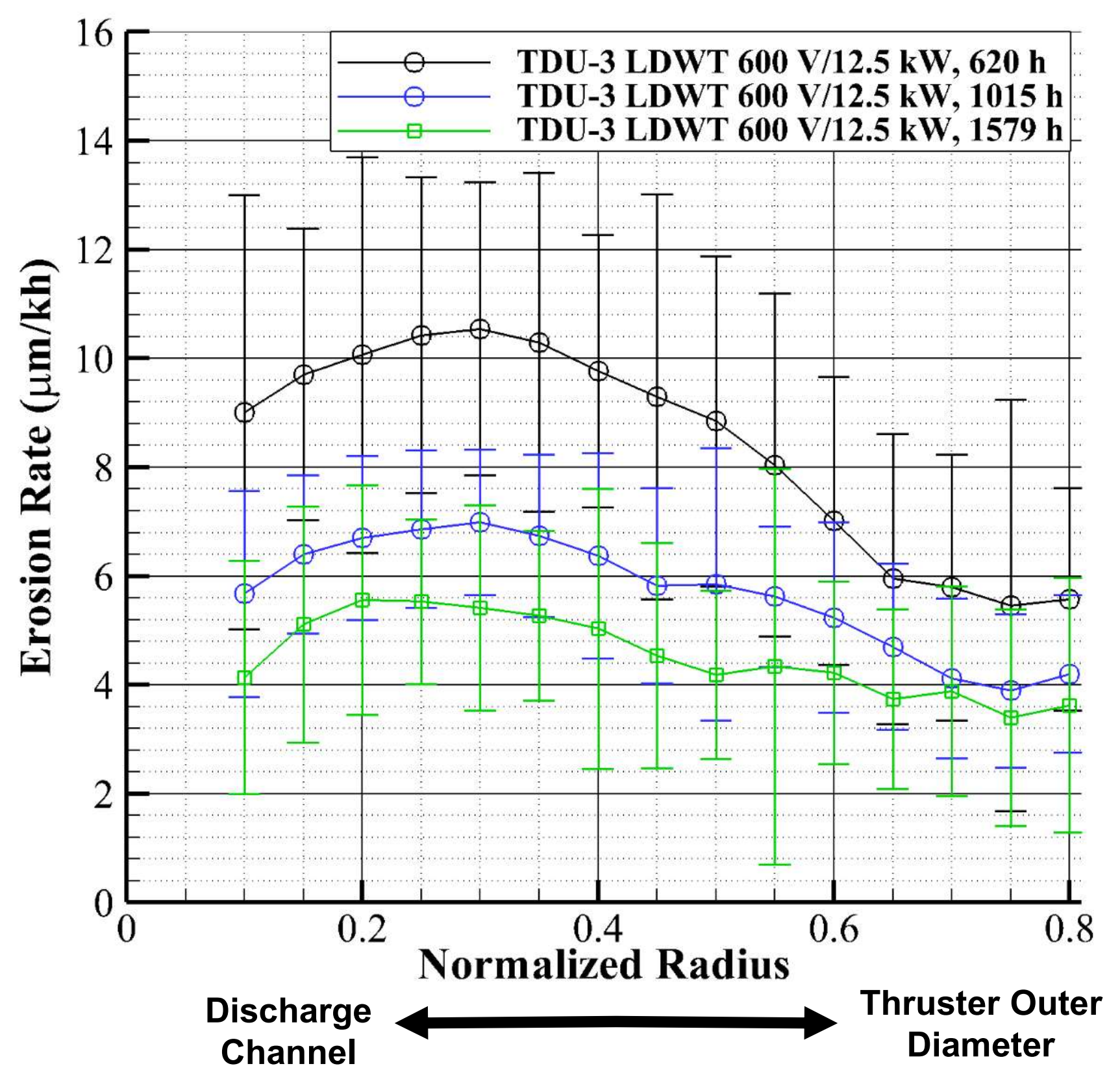

Key Observations:

1) OFPC erosion rates appear to decrease with operating time

- $\quad 46 \%$ reduction between $620 \mathrm{~h}$ and $1579 \mathrm{~h}$

- Matches trends

previously observed with the IFPC

2) Wear rates impacted by pre-test surface finish

- Plotted rates are for polished regions of OFPC

- No measurable erosion detected on unpolished sections of OFPC

3) Results support hypothesis that apparent time variation in wear is driven by pole cover roughening during operation 


\section{Results: OFPC Wear}

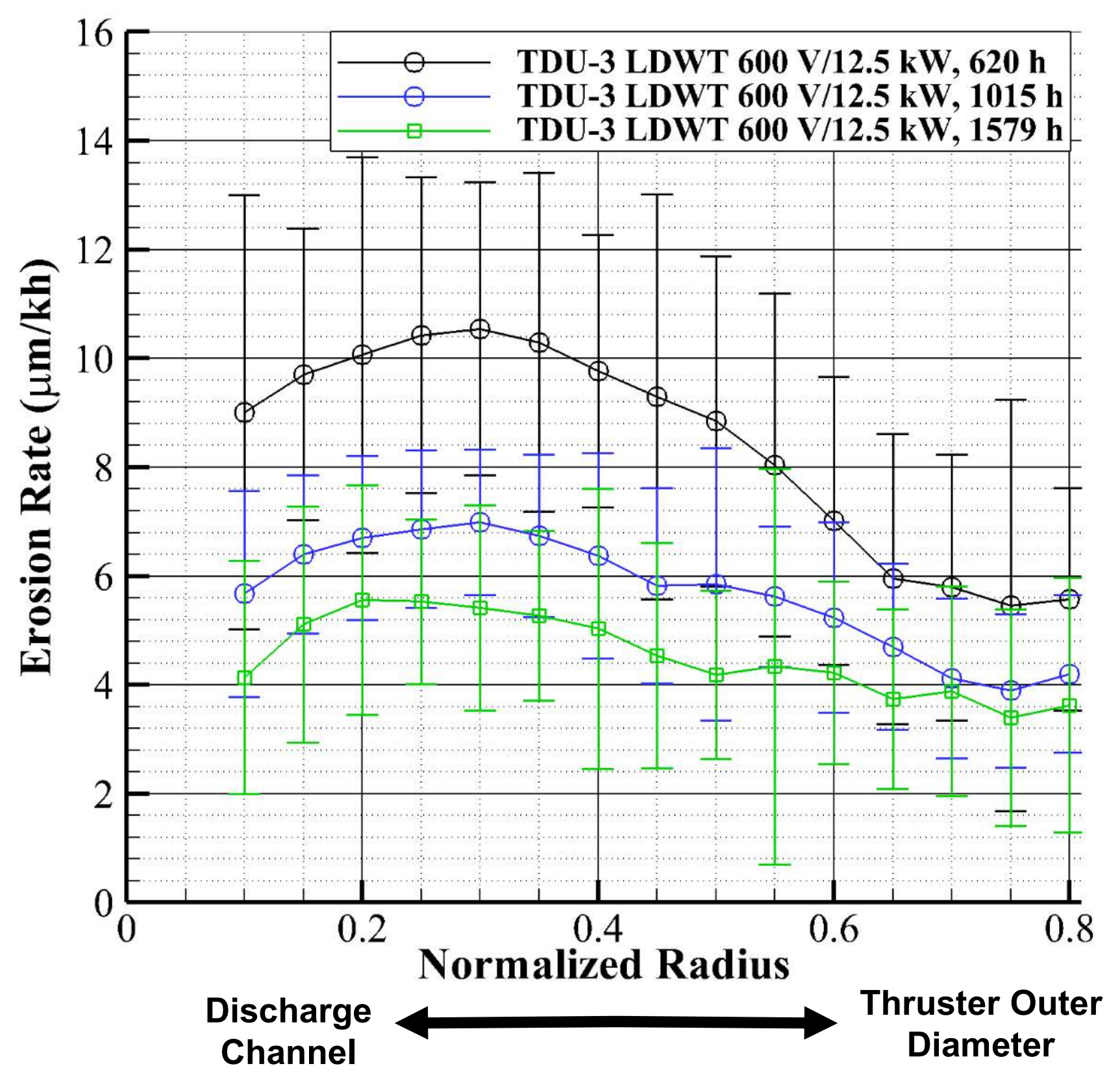

Key Observations:

1) OFPC erosion rates appear to decrease with operating time

- $\quad 46 \%$ reduction between $620 \mathrm{~h}$ and $1579 \mathrm{~h}$

- Matches trends

previously observed with the IFPC

2) Wear rates impacted by pre-test surface finish

- Plotted rates are for polished regions of OFPC

- No measurable erosion detected on unpolished sections of OFPC

3) Results support hypothesis that apparent time variation in wear is driven by pole cover roughening during operation 


\section{Results: Keeper Wear}

- Net deposition with a thickness of $\sim 1$ $\mu \mathrm{m}$ observed around the keeper orifice

- Net erosion observed at all other radii

- Matches results from TDU-1 wear test

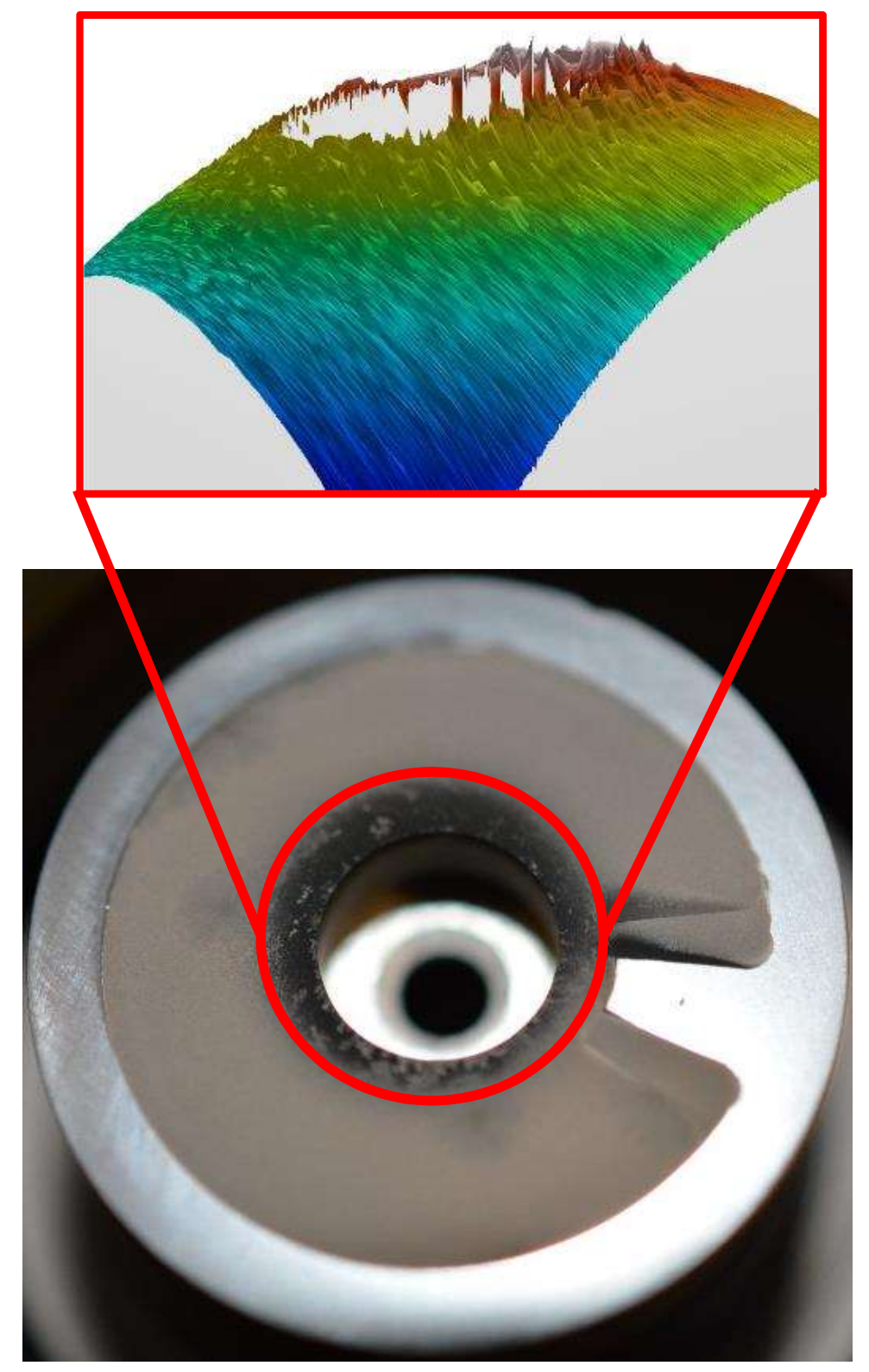




\section{Results: Keeper Wear}

- Net deposition with a thickness of $\sim 1$ um observed around the keeper orifice

- Net erosion observed at all other radii

- Matches results from TDU-1 wear test

- Net deposition also observed on one side of the keeper mask.

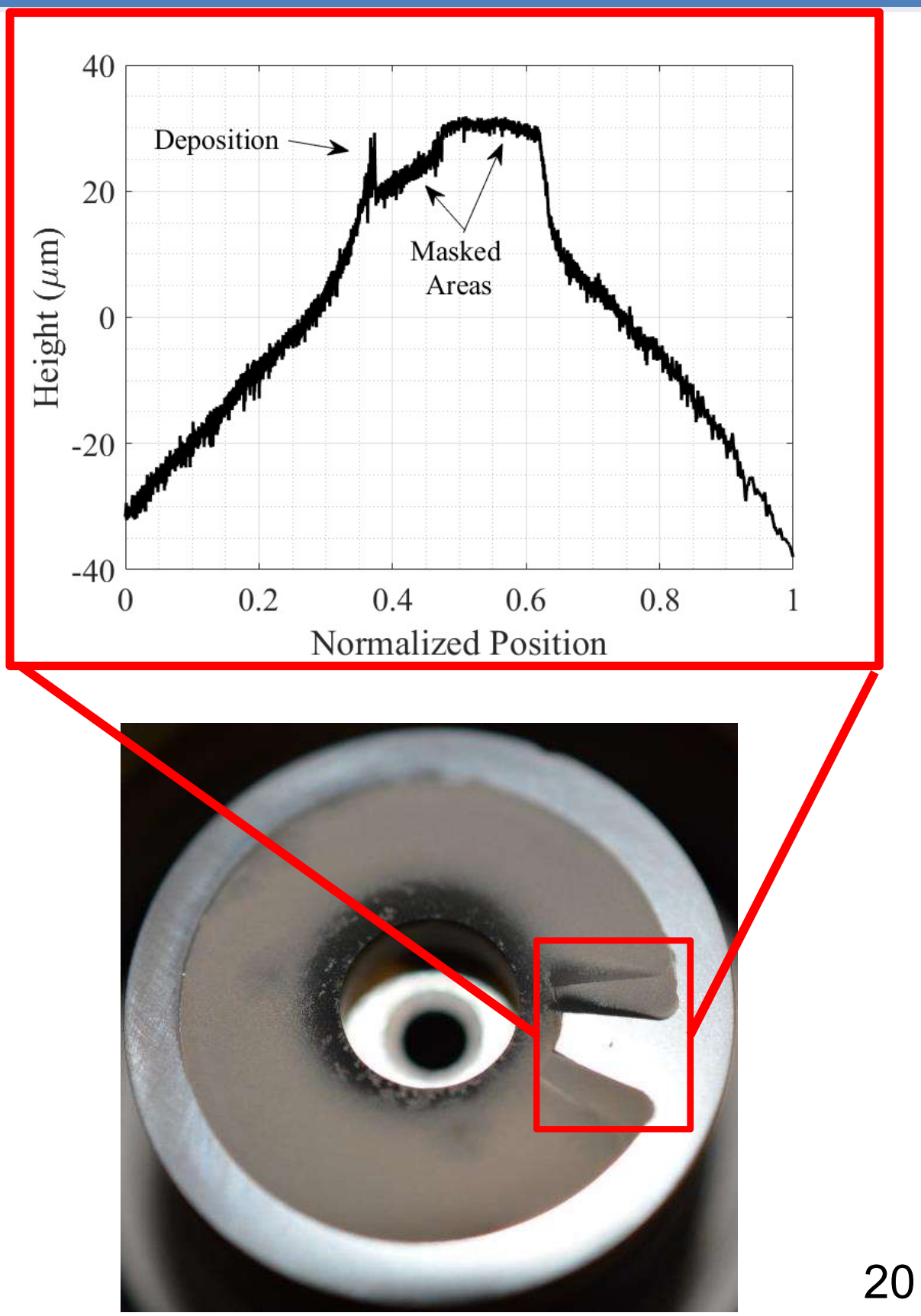




\section{Results: Keeper Wear}

- Net deposition with a thickness of $\sim 1$ um observed around the keeper

\section{orifice}

- Net erosion observed at all other radii

- Matches results from TDU-1 wear test

- Net deposition also observed on one side of the keeper mask. Possible

\section{causes:}

- Azimuthal variation in process driving keeper erosion

- Also explains step asymmetry observed during Segment I

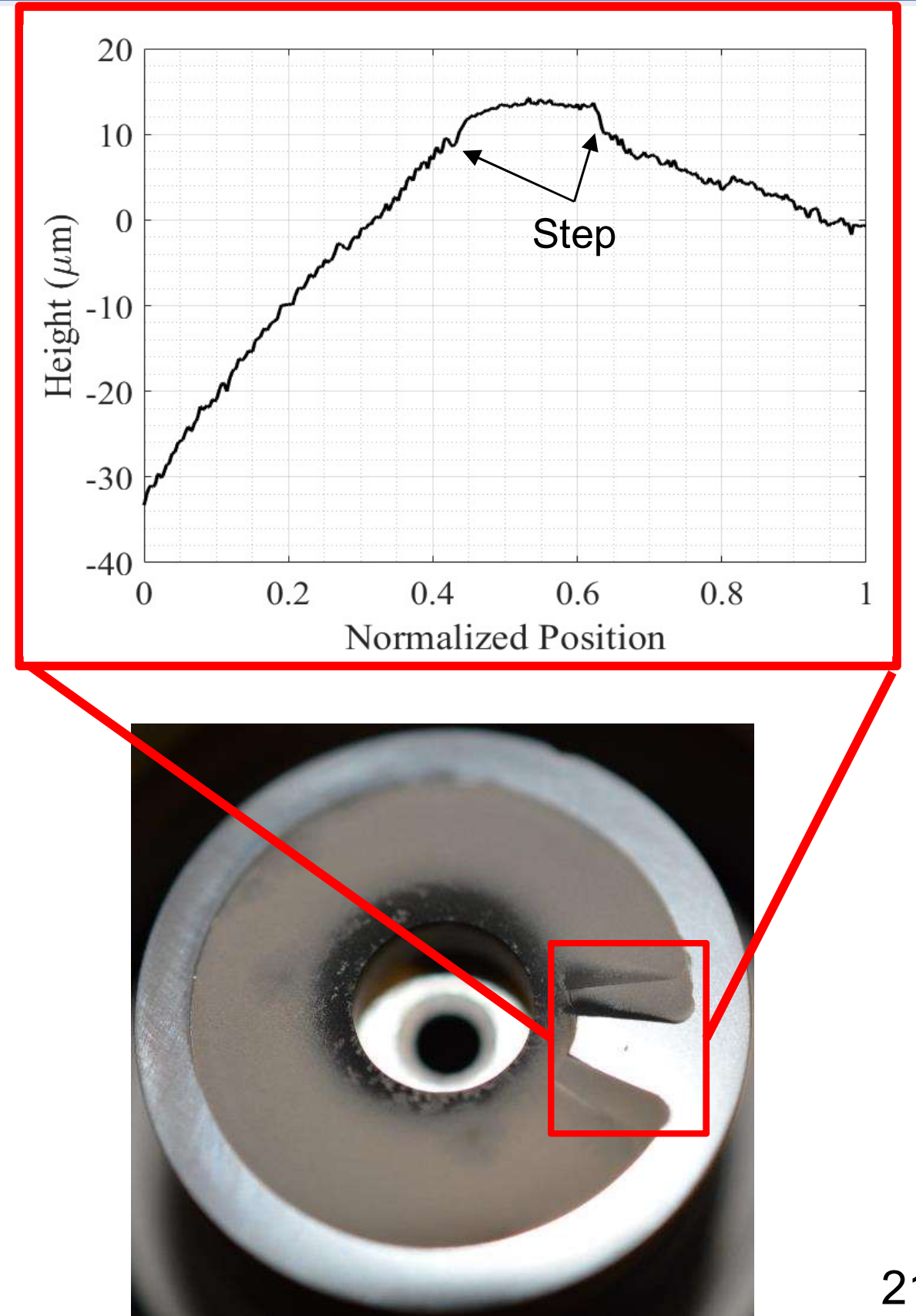




\section{Results: Keeper Wear}

- $\quad$ Net deposition with a thickness of $\sim 1$ um observed around the keeper orifice

- Net erosion observed at all other radii

- Matches results from TDU-1 wear test

- Net deposition also observed on one side of the keeper mask. Possible causes:

- Azimuthal variation in process driving keeper erosion

- Also explains step asymmetry observed during Segment I

- Accumulation of facility backsputter on one side of the horizontal mask

- Does not explain step asymmetry observed during Segment I (keeper mask oriented vertically)

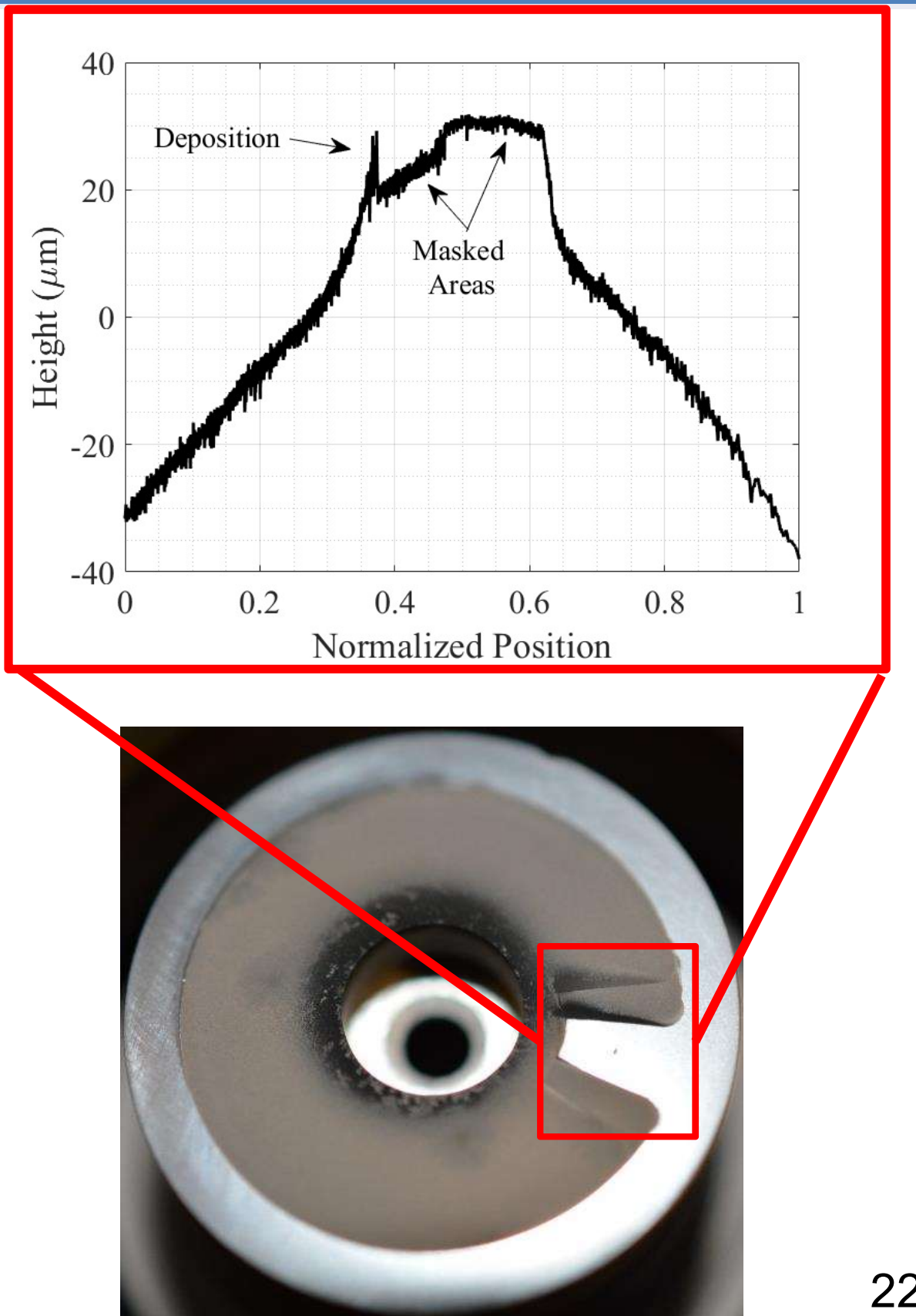




\section{Conclusions}

- The NASA HERMeS TDU-3 Hall thruster was successfully operated for 3,570 hours over six segments in a long duration wear test

- The TDU-3 demonstrated consistent performance, stability, and plume properties over the course of the LDWT and relative to previous wear tests

- Average erosion rates of a carbon-carbon composite inner front pole cover were found to match those obtained with graphite covers

- OFPC wear rates were shown to decrease with time and provided strong evidence linking this to pole cover roughening

- Regions of net deposition on the keeper suggests the presence of azimuthal variation in the process driving keeper erosion

- Overall, the TDU-3 LDWT successfully served as a pathfinder for the planned life and qualification testing of AEPS hardware by demonstrating facility readiness and component lifetimes margins of greater than $40 \%$ at the nominal $600 \mathrm{~V} / 12.5 \mathrm{~kW}$ operating condition 